\title{
Larval development in Dermatobranchus sp. (Nudibranchia: Arminina)
}

\author{
Takeshi Furuhashi', Gary Cobb ${ }^{2}$, Lesley Brooker ${ }^{1}$, Richard Willan ${ }^{3}$ \\ Faculty of Science, University of the Sunshine Coast, Maroochydore, Queensland, Australia, 4558. \\ ${ }^{2}$ Cobb Creative, 124 Greenmount Road, Buderim, Queensland, Australia, 4556. \\ 'Museum and Art Gallery of the Northern Territory, GPO Box 4646, Darwin, Northern Territory, Australia, 0801
}

\begin{abstract}
An undescribed species of the genus Dermatobranchus (Nudibranchia: Arminina), from Eastern Australia, produces a crescentshaped, cylindrical egg mass, with mean egg size of $81 \mu \mathrm{m} \times 100 \mu \mathrm{m}(\mathrm{n}=10$, $\mathrm{SD}=9,6.6 \mu \mathrm{m}$, respectively). Within one week of spawning, the eggs hatch into planktonic veliger larvae $130 \mu \mathrm{m}$ in diameter, which possess a spiral protoconch. The larvae pass through three distinct stages of development, growing to a maximum size of $170 \mu \mathrm{m}$ in diameter, prior to settling and metamorphosis into adults. There is scant knowledge available on the embryology and larval development within the Arminina, and this new species provides an insight into ontological development within this suborder.
\end{abstract}

Key words: molluse, ontology, veliger

\section{INTRODUCTION}

Opisthobranch molluscs exhibit a range of morphologies in ontological development, with three types having been documented (Gibson, 2003). The first is defined as direct development, which has been further divided into metamorphic and ametamorphic development (Hadfield et al. 1984). In metamorphic development, the larvae exhibit a veliger stage and/or larval organs before hatching, while in ametamorphic development, no veliger stage exists prior to hatching. Opisthobranchs that exhibit direct development typically lay large, yolky eggs, for example, the arminid Dermatobranchus striatellus Baba, 1949, whose eggs are $215 \mu \mathrm{m}$ in diameter (Hamatani, 1967). In this species, embryonic development, followed by metamorphosis, occurs in the egg capsule, with direct hatching of the adult-like juveniles. In the second type of development, the veliger larvae are termed lecithotrophic. They are free-swimming for a period extending from just seconds to days, prior to settling and adult metamorphosis. Opisthobranchs that exhibit this type of development usually lay moderate to large eggs with ample yolk, for example, the pleurobranch Berthellina citrina (Ruppell \& Leuckart, 1828), whose eggs are 110-250 $\mu \mathrm{m}$ diameter (Gibson, 2003). In the third type of development, the veliger larvae are termed planktotrophic. They are free-swimming for a considerable period of time (typically exceeding 10 days) and feed on plankton (Kriegstein, 1977). In comparison to opisthobranchs exhibiting the other two types of development, their eggs are relatively small, for example, the sea hare Aplysia dactylomela Rang, 1828, which lays eggs that are $40-170 \mu \mathrm{m}$ in diameter.

In addition to the different types of larval development, nudibranchs also display two protoconch morphologies (Page, 2000). The predominant shape exhibited in the order is a spirally coiled shell (type 1 ). In contrast, type 2 protoconchs have an inflated egg shape. Both types of protoconch may be shed at metamorphosis, or retained as an external or internal shell.

There has only been one previous brief investigation into larval development in the Arminina, on the genus Dermatobranchus by Hamatani (1967). In that study, Dermatobranchus striatellus was shown to lay eggs that are $215 \mu \mathrm{m}$ in diameter, and to hatch as crawling juveniles at around 10 days. The protoconch is classified as type 1 , being colorless, transparent, and spirally coiled. Hence, there is extremely limited information available on larval development in Dermatobranchus species, and there is a need for more detailed descriptions of members of this genus.

The species of Dermatobranchus that is the subject of this short contribution is a new species that is externally most similar to the Japanese $D$. primus Baba, 1976. Images of this species can be found on the website maintained by Cobb and Mullins (2005). This species is presently being described by Willan and Cobb. 


\section{MATERIALS AND METHODS}

In excess of 20 egg masses of Dermatobranchus sp. were collected subtidally, along with adult specimens, during the month of March, at Mooloolaba (Sunshine Coast, Queensland,
Australia). Three adult specimens were also observed laying egg masses in the laboratory. With the exception of one egg mass, all were measured prior to return to the precise site of collection. The remaining egg mass was incubated at $25^{\circ} \mathrm{C}$ (the

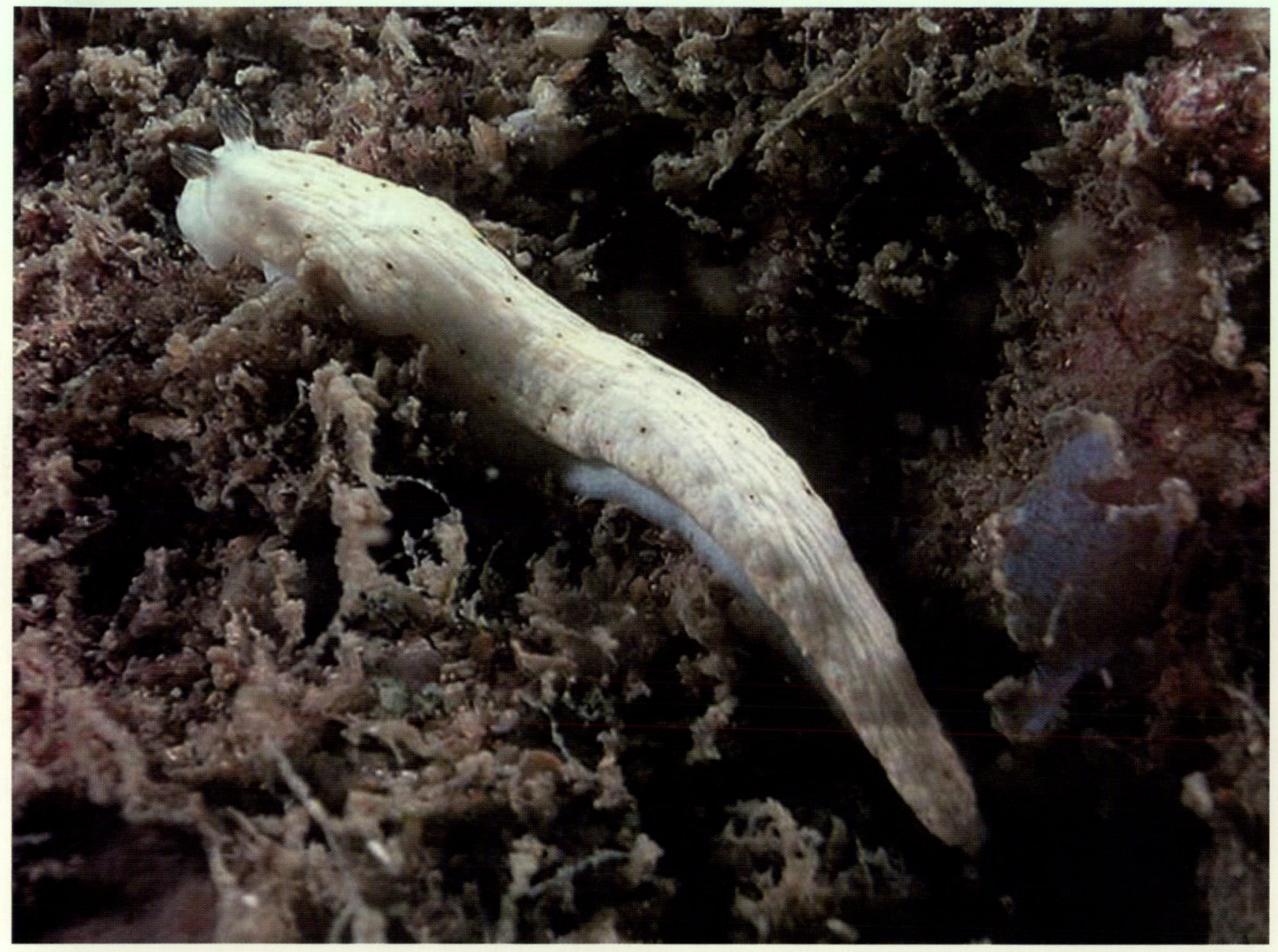

Figure 1 Dermatobranchus sp. (adult specimen $21 \mathrm{~mm}$ long).
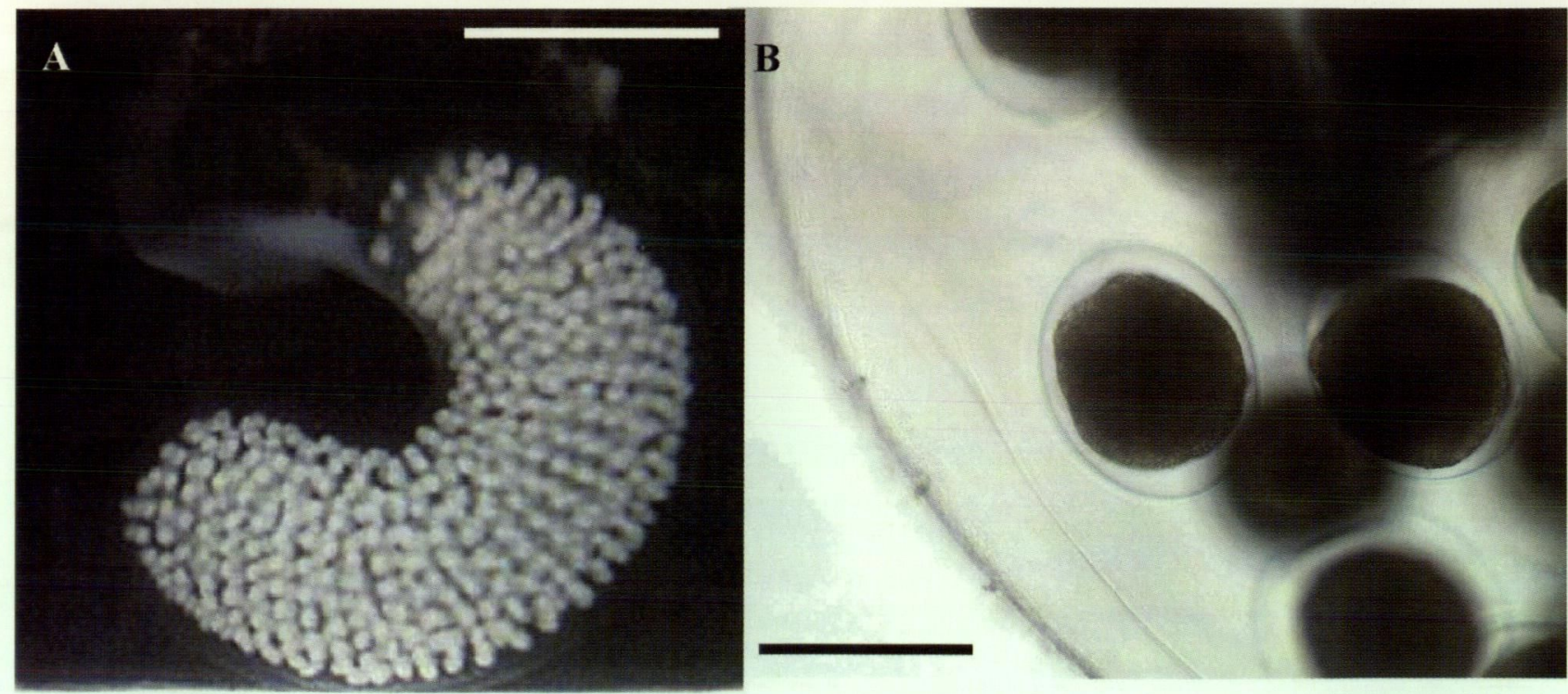

Figure 2 Light micrographs of $\mathbf{A}$, cresent-shaped, cylindrical egg mass attached by a stalk to the substrate. Scale line = $1 \mathrm{~cm}$; B, individual eggs just prior to hatching. Scale line $=100 \mu \mathrm{m}$. 
A

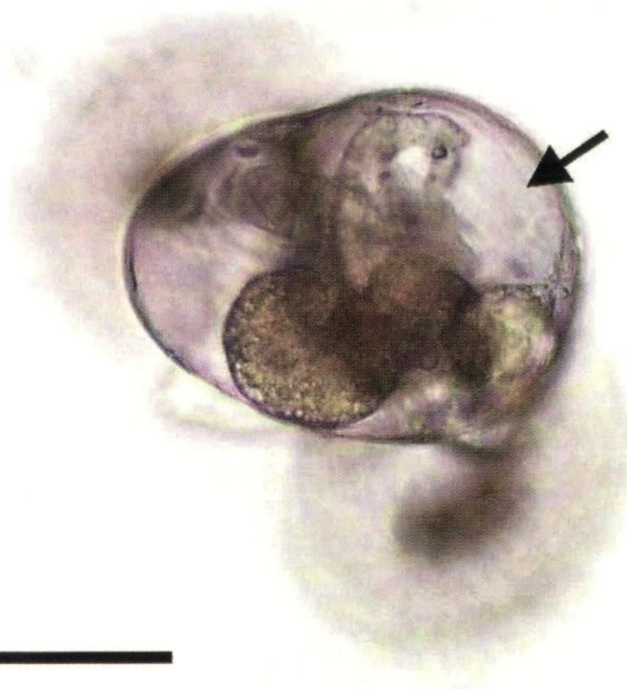

C

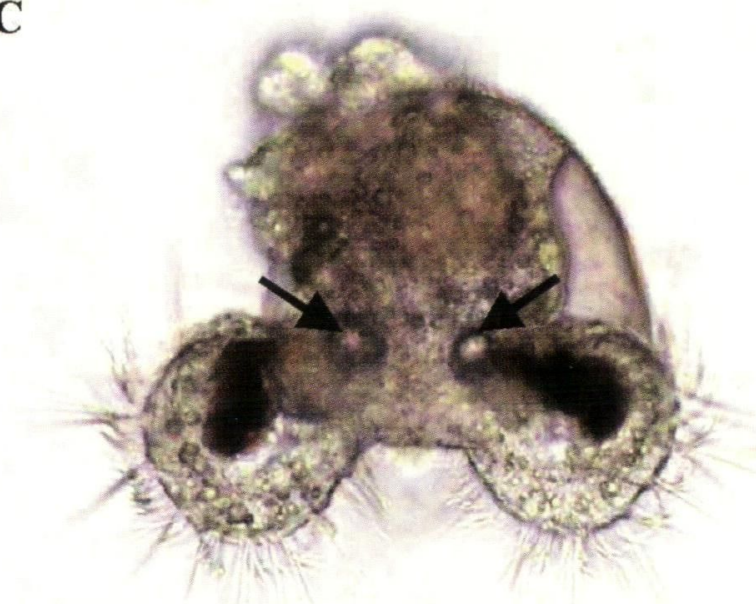

B

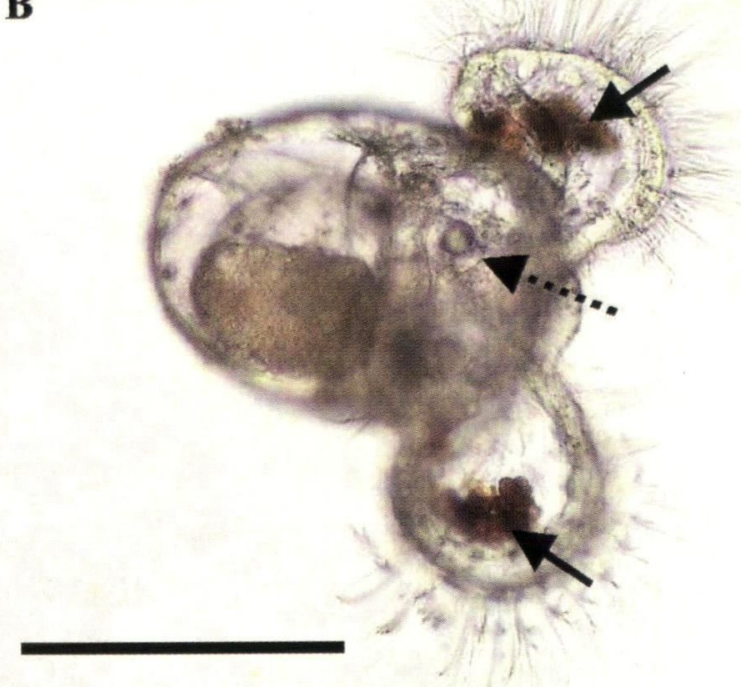

D

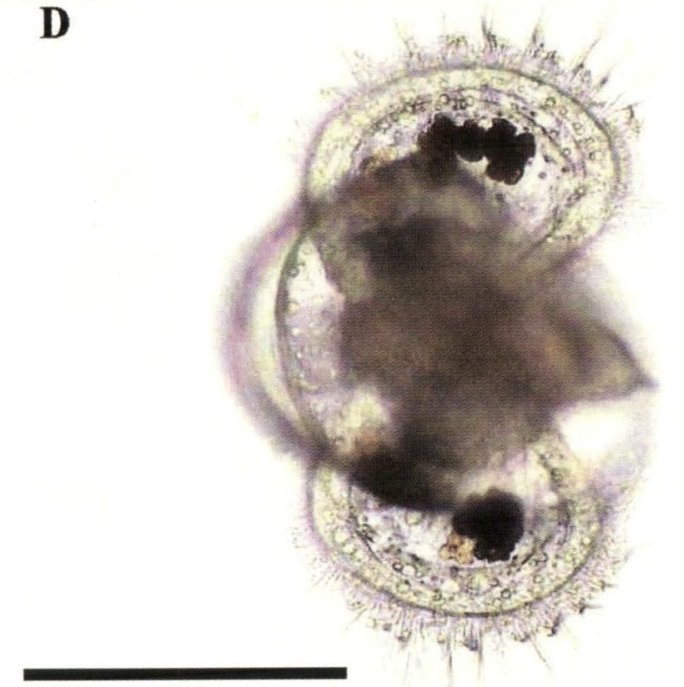

Figure 3 Planktotrophic veliger larva after hatching: A, postero-dorsal view showing the purple protoconch (arrow); B, dorsal view showing the presence of brown granules in the velum (solid arrows), and a statocyst (dashed arrow); C, anterior view showing two statocysts (arrows) and D, dorsal view showing brown granules in the velum. Scale lines $=100 \mu \mathrm{m}$.

same temperature as the seawater at the time of collection) in a glass bowl filled with seawater, with weekly exchanges of fresh seawater. Hatched larvae were successfully kept alive for five weeks but they failed to metamorphose into adults.

Veliger larvae were removed at regular intervals (approximately weekly), and developmental stages observed with the aid of an Axicoskop 2 MOT (Zeiss) light microscope, and photographed with an Olympus DP10 digital camera.

\section{RESULTS AND DISCUSSION}

Dermatobranchus sp. (Figure 1) lays a white, crescent-shaped, cylindrical egg mass (Figure 2a) that is $1 \mathrm{~cm}$ in diameter at its widest point and $3 \mathrm{~cm}$ across at the widest point of the crescent. As the egg mass is being laid it curls up and over the back of the animal, prior to being attached to the substrate by a jelly-like stalk (Figure 2a). This morphology of the egg mass is consistent with those categorised as "Type D" by Hurst (1967). The egg mass is filled with smooth, oval capsules, each containing a single egg with a mean size of $81 \mu \mathrm{m} \times 100 \mu \mathrm{m}(\mathrm{n}=10, \mathrm{SD}=$ 9, $6.6 \mu \mathrm{m}$, respectively) (Figure $2 \mathrm{~b}$ ). The eggs hatched after seven days into veliger larvae (130 $\mu \mathrm{m}$ diameter) with a purple type 1 protoconch (Figures $3 a-b)$. Within a few days of hatching statocysts were visible and brown granules were obvious in the velum (Figures $3 c-d$ ). The digestive gland was deep green in colour, indicating that the larvae may have been feeding on microalgae obtained from the seawater. The granules in the velum disappeared after 8 days (Figure 4), by which 
$\mathbf{A}$

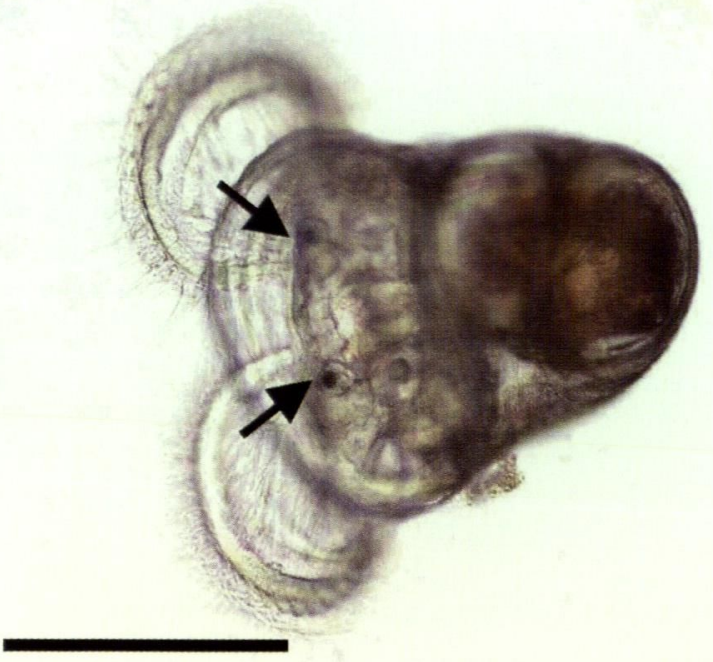

B

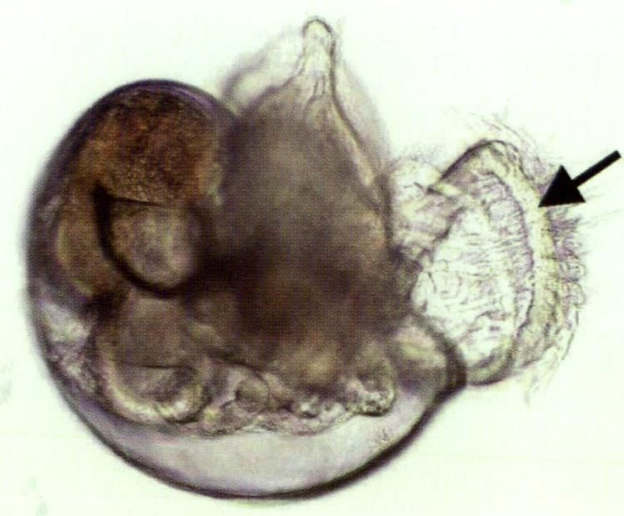

Figure 4 Veliger larva 8 days post hatching, showing: A, eyes (arrows); and B, velum without granules (arrow). Scale lines $=100 \mu \mathrm{m}$.

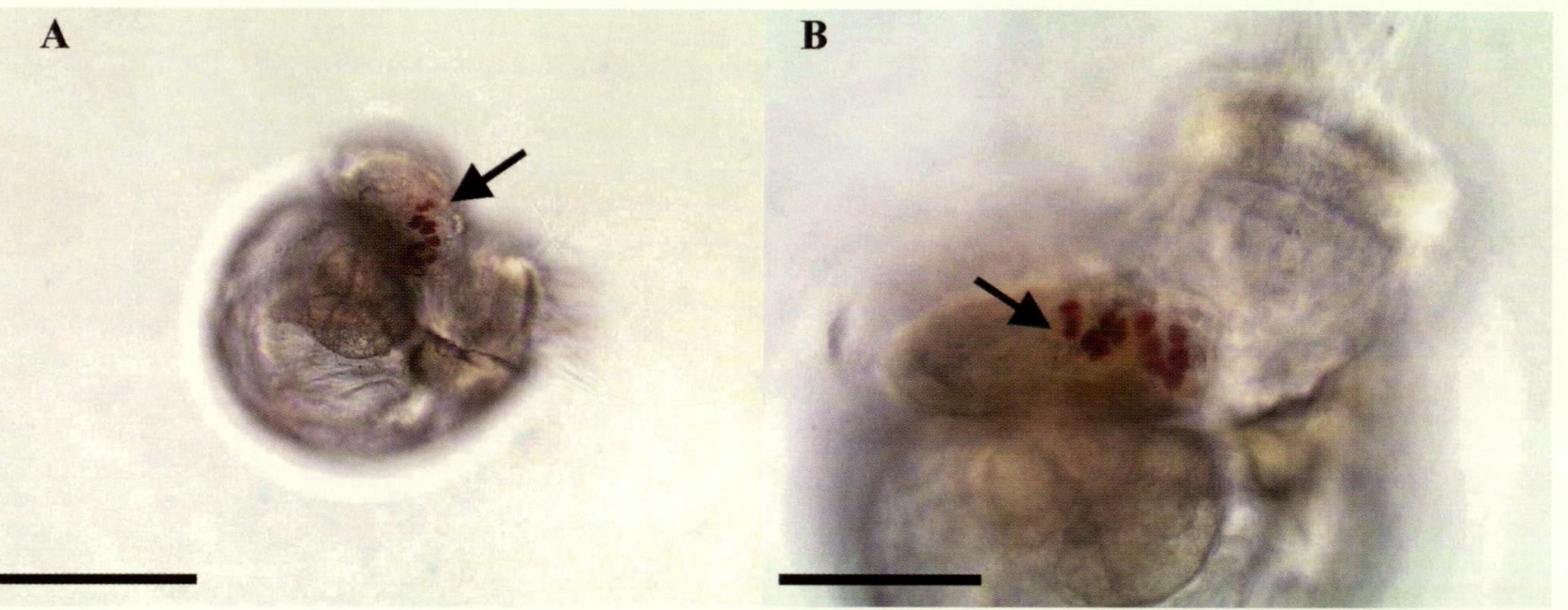

Figure 5 Veliger larva 17 days post hatching, showing: A, a clump of red granules in the developing foot (arrow); B, higher magnification of the red granules (arrow). Scale lines $=100 \mu \mathrm{m}$.

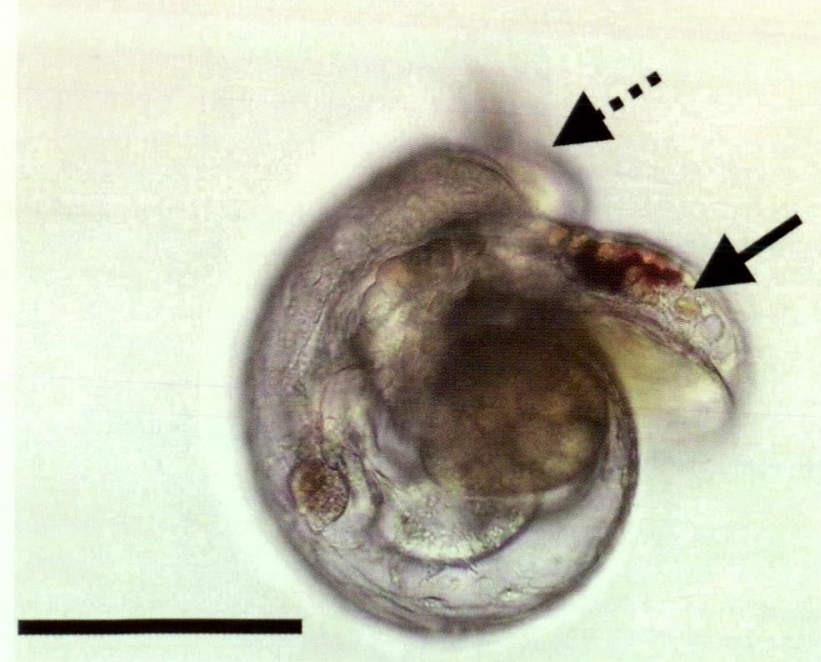

Figure 6 Veliger larva 35 days post hatching, showing a well-developed foot (solid arrow) and a reduced velum (dashed arrow). Scale line = $100 \mu \mathrm{m}$. stage the eyes were developed and the protoconch had attained its maximum size of approximately $170 \mu \mathrm{m}$ in diameter. At 17 days post hatching an operculum was apparent (although it was most likely present during the whole larval stage), the velum was reduced in size and the well-developed foot contained clumps of red granules (Figure 5). By 35 days post hatching the foot had developed further and the cavity between the intestines and protoconch had enlarged (Figure 6).

The larval development of this species is similar to that reported for other nudibranchs that have planktotrophic larvae. However, in comparison to Dermatobranchus striatellus (Hamatani, 1967), this species has smaller eggs. In addition it has a long pelagic period as a veliger larva, while $D$. striatellus does not have a free-swimming larval stage. While both species possess granules of unknown aetiology in the velum and the foot, in D. striatellus they are arranged in a row along the edge of the tissues. In 
contrast, they are clumped in the species investigated here. The presence of these granules has not been reported in other nudibranch genera, and deserves further investigation.

\section{REFERENCES}

Cobb, G. H. and Mullins, D. (2005). Opisthobranchs of the Sunshine Coast, Australia. http:// www nudibranch.com au.

Gibson, G. D. (2003). Larval development and metamorphosis in Pleurobranchaea maculata, with a review of development in the Notaspidea (Opisthobranchia). Biological Bulletin 205: 121-132.

Hadfield, M. G. and Switzer-Dunlap M. (1984). Opisthobranchs. In A. S. Tompa, N. H. Verdonk, and J. A. M. van den Biggelaar (eds). The Mollusan (Reproduction). Academic Press, New York. Pp. 209 350.
Hamatani, I. (1967). Notes on veligers of Japanese opisthobranchs. Publications of the Seto Marine Biological Laboratory 15(2): 121-131.

Hurst, A. (1967). The egg masses and veligers of thirty Northeast Pacific opistobranchs. The Veliger 9: 255188.

Kriegstein, A. R. (1977). Stages in the post-hatching development of Aplysia californica. Journal of Experimental Zoology 199: 275-288.

Page, L. R. (2000). Inflated protoconchs and internally dissolved, coiled protoconchs of nudibranch larvae: different development trajectories achieve the same morphological result. Invertebrate Biology 119(3): $278-286$. 